\title{
Analysis on the Typical Genre of Traditional Folk Songs in the Northeast
}

\section{Sichuan}

\author{
Ling Yang ${ }^{1}$ \\ ${ }^{1}$ School of Music,Leshan Normal University, Sichuan, China \\ a43182084@qq.com
}

Key words: Northeast Sichuan,Traditional folk song,Typical genre

\begin{abstract}
This paper takes the discussion on the traditional folk songs in the northeast Sichuan for its four typical genres: song of paddy activity, song of people carrying goods on back,folk custom song and song of lantern and the aim is to arrange and discuss their formation, development and artistic characteristics.
\end{abstract}

\section{Introduction}

Northeast Sichuan, Shanxi province to its north, Chongqing to its east and south, Nanchong and Mianyang to its west and north, the inner region has steep terrain, high mountain and deep river, which with Han River to its north, Zhou River and Ba River to its south, Daba Mountain and Micang Mountain in its center and the area of it is about over 30 thousand square kilometers and the population is about over 10 million. Because in the early period of $1930^{\text {th }}$, in this area, the Fourth Front Army of the Chinese Workers'and Peasants'Red Army led by Chinese Communist Party created Sichuan-shaanxi revolutionary base, which ranks only second to Central Soviet Area, the people in Sichuan call this area old revolutionary base areas. As for this old liberated area is located in the district of Daba mountains, which complex mountain chain and drainage lead to the various lanforms and climatic characteristics and these factors also creates gorgeous and colorful folk song cultural resources. This paper takes discussion on the characteristic typical genres of traditional folk song in old liberated area to explore their formation, development and artistic characteristics.

In counties of old liberated area, such as Xuanhan,Wanhan,Tongjiang, Nanjiang, one synthetic art form of songs of paddy activity, which combining song type of singing together and attacking by gong and drum, is very popular in that region and the local people called this type of music weeding song or gong and drum song. The so called song of paddy activity is local folk and the story about it is that, in old days, country people in old liberated area when the people take weeding and paddy activities, in order to add fun to which, people will arrange one person beats a drum and one person beats a gong along by singing songs in ridge or hillside. According to the recordation of Bazhou Record, 'in the years of emperor Kangxi and emperor Yongzheng,spring rice transplanting in Sichuan with two person singing, beating drum and gong, beautiful songs will be heard from ridge, beautiful melody making cultivator forget fatigue and be more energic. [1] That is the record about the working activity of country people in spring season, which has folk song singing with gong and drum sounds and it can improve labor enthusiasm and working efficiency and to make people work in a lively and pleasant atmosphere. This type of folk song is especially popular in busy season, which performance firslty is the large scale with at least 30 persons to form one percussion, in 
which two or three leaders with talking and singing ability in front of the crowd and the two or three person singing and beating drum and gong simultaneously. Secondly, its performance is the large quantity of troops,sometimes, there will be five or six percussions playing simultaneously and forming one grand and marvelous situation of great momentum, which will create and the high-pitched sound of singing makes the surrounding shake and mountains resound.

The origin of this type of folk song is earlier in Sichuan district,and there are already beating-drum figurine in pottery figurine earthed in Han dynasty tombs in old liberated area, and there are images of drum-beating pepple in cropland appearing in bricks with Han dynasty pictures in it. To Northern Song Dynasty time, this art form maybe to take shape, Chinese poet Sushi has recorded in his peom that, 'In February, farm work begins.In early April,green millet and lush grass dancing, cultivators walking out to work with a number about a hundred.Taking a sand clock as timekeeping, beaing drum to call people together. Choosing two prestigious people, one beating drum one taking sad lock. Peole starting working or stope working according to this two people's signal. Not coming people after the drum sound or already coming people do not work all should get punishment.'[2] From the description of this poem, we can know that, this type of folk song generally will be played by two prestigious professional singers with rich productive knowledge and experience. They often choose ridge or hillside as the place to play with talking first or singing first or talking and singing at the same time to conduct the working farmers. This two persons have to match up tacitly to make the gong sound and drumbeat mixed together properly and also they need improvisation accoring to the actual working situation to praise positive workers and spur on lagging persons. The aim is to inspire labour enthusiasam, supervise working situation and improve production efficiency. The close relation between this type of folk song and the rhythm of working people in old liberated area promote the forming of art characteristics of straight singsong and short-small structure.

Folk song form---song of people carrying goods on back,is the typical lyric song, and it is the national intangible cultural heritage with a history of about three thousand of years, and it originates from a particular period, during which,people in Sichuang distric sing songs when they carry goods through Micang ancient path for a long distance journey. The characteristic of this form

of folk song has extended tone, free rhythm, superimposed singing ways, not too complicated structure and work song-similar yo-heave-ho in beginning and end of one song because in that particular period, large scale of goods-carring troops often walk through steep intermontane to transferring rations and forage,weapon and daily living equipment for interchange of material in this long-distance journey. Furthermore, because of the heavy labour intensity, the porters need to spend much time resting, therefore, there are many description for the hardship of labour, which frequently has plentiful emotion,exquisite melody and exuberant temperament and interest.

Generally speaking, this form of folk song is single-section style with two phrases and it does not have complicated structure of changing and concluding, and its vocal music is male voice moslty with falsetto and high tune system, which is resounding and melodious and buzzing. The most characteristic is that many songs of this type has Shuaiqiang with long breath and short sigh 'Yeah-Hei', which seems can gets through the cloud and fog and tramps over hill and dale and it can particularly express the rough and uninhibited feeling and bravuraperformance momentum. This type of folk song is popular in the counties of Tongjiang, Nanjiang, Changping,Wanyuan etc in old liberated area.

Minor can also be called 'Shidiao'and 'Ditty', which is the folk song for pastime and expressing one's emotion after working and it can refelects extensive society life. The popular minor music in old liberated area are custom song, love song,complaining song, children's song etc, among which, 
custom song plays an extremely important role in old liberated area folk songs. Custom songs will be song in particular protocol or ceremony and it has a high degree of lifelization, which is a typical minor music . Generally speaking, the structure of custom songs is longer and bigger than common minor and it often appear in the form of tune cluster, even divertimento and the common custom songs in old liberated area are marriage fencale songs and filial song.

Marriage fencale songs are also called wedding lament and sitting marriage song, and it is song for when young girl get married. In early period in old liberated area, there are customs that, in the night before the bride gets married, inviting good friends to gather in bride's house to sing songs far into the night even all through the night. There is one wedding lament in the central district of Sichuan, the content of which is 'Wind blows osmanthus fragrance to nose, mom takes lamp to my room, today you can see me in this room, tomorrw only a empty room left here' , from the four sentences, we can read mom and daughter's sadness before the marriage. Custom of singing sitting song has a history about over a thousand years in south China, Chinese geographer Zhou Qufei in Southern Song Dynasty decribed in his work Ling Wai Dai Da that, 'The night before marry daughter off,the dressed-up new couple sitting in royal court, dressed -up bride with finery accessories, sad and mild face with successive singing around the ear, people around express their blessings to their long happy marriage, saying goodbye words to their playmates since the childhood. ' in Dao-guang period of Qing dynasty,Yongzhou Mansion Record records that '... Four female singers lead bride to house, parents to the guest place. To night, singing begins with group of girls around, married woman come with others to here, that is the description of sitting marriage song. ' Since Ming and Qing dynasties, Sichuan is one typical immigrant society,some scholars make presumption that the custom of sitting marriage song came to Sichuan province with the immigrant of Hunan province and Guangzhou province to Sichuan province. The tune of marrige song is full of vivid local flavor and has obvious verbalization tendency, which can reflect complex emotional changes, which is humorous or tragic or affectionate or gloomy, and the structure is easy to remember, besides, the situation of songs with same melody and different lyric is common and the frequent singing forms are solo, unison, leading singing, antiphonal singing etc.

Filial song is also called 'filial song auditorium'or 'night gong and drum'or call it directly funeral song, funeral drum, disturb funeral or crying funeral, which is the ceremonial songs when watchers take wake for died person and generally it is song by group singers invited by beravement host in the form of sitting in mourning hall. For this type of songs, except for human voice singing, it also needs sets of gong and drum as accompany. Filial songs has been popular in rural towns of east Sichuan many years ago,and the Daningxian record of constructed Chongqing wizard stream in Guangxu year of Qing dynasty records that, ' No sacrificial rites at night, people play drums and gongs mutually matched, that is called funeral drum '. The lyric of filial song in old liberated area is made according to popular folk history stories, such as Twenty-four Filial Piety to achieve the aim of wake, mourn,contribution and education. The singing of this type of song is required to conduct according to definite procedure, such as singing Song-building in first night, Song-dividing in last night. Every night's singing has its definite order, generally, the content of head and tail section should have relation with beravement and in center section, some songs about streets and lanes can be song to diver themselves from the long night. The characteristic of chanting is the distinguishing feature of filial song melody in old liberated area, and its tune is sorrowful, low,sad and mild and plaintive and in most cases, it will have longer prolongation of tune, the singing forms are solo and unison, and sometimes, it will borrow the leading singing vocal accompaniment of high-pitched tune in Sichuan opera. The representative filial songs are Twenty-four Seasons Song in Dazhu county, sacrificial song Visiting Grave of Chen Yulan in Wanyuan county, etc. 
There is also one popular type of love song with extremely rich characteristic and complex form, which belongs to the lantern songs of traditional folk song. Lantern song is the traditional singing and dancing music with full-bodied vitality and typical local color, and it has two performing forms. The first form is the so called 'Light-playing', which is collaborative singing by one female heroine similar to Dan (Chinese opera) and one actor similar to buffoon. The actress ‘Dan’is generally called by common people 'Yaomeier'(nickname for young girls), which main dance movement are 'turning the mill with single arm' and 'salix leaf swing with single arm' and the performance is cute and beautiful. The actor buffoon takes prop in hand, mostly is cattail leaf fan and sometimes the actor will wear mask, besides, the main dance movement are 'dance step like stump' and 'salix leaf swing in wind'. They dance and sing at the same time to express directly the feeling of intimate lovers with funny and humor libretto and performance. Because the performance form is singing and dancing joyously with well arranged dance and sweel-and-swale movement, it needs certain expressive space and the outdoors performance is the main form. [3] Its performance is lively and vivid with full of wit and humor. Another song type is lantern songs, which is commonly known as 'single lantern' or 'single drama' and it belongs to small local operas with song and dance,besides, it already has the rudiment of roles 'Sheng'(Young man), 'Dan' and 'Buffoon' and it frequently use folk melody and easy character role to express story line.

The history of lantern songs origin is long, and about the saying of its origin in Xiushan Chongqing, the traditional aria Starting Lantern records that, ' Lantern song originates from Tang dynasty and becomes prosperous in Song dynasty. Chinese emperor Renzong ascends the throng, his mother becomes blind. Decreeing making three thousand and six hundred red lanterns, talking detailed to you about these lanterns. Throwing two thousand lanterns into Yangtze river, earth immortal taking away one thousand lanterns. Left five hundred and ninety-eight lanterns for abstinence hall. To today, only two of the wish lanterns in emperor Renzong imperial edict'. [4] In order to make his mother to see the world again, Renzong gives orders arrange three thousand and six hundred lanterns to decorate the capital, which makes the lantern be the symbol of disease-curing, calamity preventing and blessing. Hence, for about thousands of years, in any festival, people in old liberated area are enthusiastic in singing lantern songs. The melody of lantern songs is fluent and graceful, and because of the form of sing and dance, lantern song puts more attention on the dance characteristic and the structure is generally small and short. The most representative lantern music in old liberated area are 'Moving lantern tune' in center of Sichuan, 'Carriage lantern tune' in Qu county, Money Stick in Xuanhan district, Dragon Boat Song in Wanyuan district and Fishing Songs in Tongjiang district etc.

The traditional folk songs in old liberated area of northeast of Sichuan is the traditional music culture with local inherent morphological characteristics, which is created by old liberated area people by taking local inherent ways and adopting local inherent forms. The traditional folk song originated from the combination of people's labor practice and production life in northeast of Sichuan is not only the description of vivid society life history about old liberated area image, but also the epitome of traditional culture about Daba Mountain. However, after all traditional folk songs comes from certain society background and productivity condition, so it must be conformable with popular life-style. Once the society life has great changes, then changes will happen in folk custom, which will further promote folk song flow along with folk activity. Besides, this change can be epochal and also can be regional and during the course of changing, the folk song with great differences to real life will be limited inevitably by epoch, and then it will lose the lived on'soil' . But, we have to recognize with conscious version the culture value of traditional folk song as precious culture heritage in old liberated area, and as the proposita for the heritage and development 
of old liberated area history culture for thousand of years, it bears rich culture information of old liberated area people ancestors and elder generation, which can be talked endlessly, from this point, there is everlasting significance for its exploration, protection and heritage.

\section{Acknowledgements}

Funding project for Development And Research Center,Sichuan Old Revolutionary Base Areas

(Number: SLQ2014C-12.)

\section{References}

[1] Z. P.Chen, The Canal Folk Literature and Folklore Studies [M]. Chengdu: Sichuan University Press, 2001:147-148. (In Chinese)

[2] Sichuan Literary Federation.Sichuan Folk Ceremony[M].Chengdu:Sichuan People's Publishing House,1999:73. (In Chinese)

[3] W.Z.Wen,editor-in-chief,Sichuan-The Land \& the People.Chengdu:Sichuan People's Publishing House,1985:458-459. (In Chinese)

[4] Editorial board of China Dance Record.Sichuan-China Dance Record[M].Shanghai:Xuelin Publishing House,2014:45-46. (In Chinese) 